\title{
Preparing students for community-based learning using an asset- based approach
}

\author{
Lisa Garoutte $^{1}$ and Kate McCarthy-Gilmore ${ }^{2}$
}

\begin{abstract}
One goal of service and community-based learning is to produce students who are more tightly engaged in the larger communities surrounding their institutions. Drawing on data from three courses, we argue that an assetbased approach plays a role in creating authentic campus-community partnerships that strive to engage students as members of the community from the outset and throughout their service learning courses. Asset-based activities help students come to understand the value of relationships amongst community members while also underscoring the value of their individual role in this group. As such, students are more prepared for future work within the community.
\end{abstract}

Keywords: Asset-based; community-based learning; asset mapping; community engagement

Like many other institutions of higher education, our small Midwestern Catholic College has integrated the principles of service and community-based learning into the school's mission. Faculty, staff and students alike are prompted to "learn actively" and "contribute responsibly" both on and off campus. The academic response among faculty has been to incorporate community-based learning into class content across a wide array of disciplines. The challenge for faculty using a community-based approach is how to create an experiential learning component that delivers the benefits of service or community-based learning, for students, colleges, and communities, while also avoiding the challenges (such as reinforcing privilege) associated with this pedagogical approach.

Drawing on data collected from six courses, we argue that guiding students through experiential learning activities that rely on elements of asset-based community development is one way to achieve this goal. We find that using this approach to prepare students for community-based learning in courses results in several benefits for students including a stronger connection to and personal investment in the local community, and a greater understanding of communities generally. It also gives students a skill-set from which to draw from in future community work. As a result, we find elements of asset-based community development provide a solid foundation for future utilization of community-based learning in academic courses, which is in-line with best practices for service and community-based learning (NSEE, 2014).

\section{Advantages and Challenges of Community-Based Learning}

There is considerable research that demonstrates the successes of community-based learning techniques. Community-based pedagogies, for example, provide an opportunity for personal growth among students, augment GPA, and are associated with the development of critical thinking skills (Eyler \& Giles, 1999). Service learning also appears to enhance students'

\footnotetext{
${ }^{1}$ Loras College; 1450 Alta Vista, Dubuque, IA 52001

${ }^{2}$ Loras College; 1450 Alta Vista, Dubuque, IA 52001
} 
understanding of their role in the larger social world. Peterson (2009), for example, argues that students "...make the connection between getting involved in local community-campus partnerships that better their immediate surroundings as well as have direct consequences for the global communities that are effected by the actions, and inactions, of the US citizenry" (p. 549). Likewise, Battistoni et al. (2009) tell us that "By engaging them with a variety of volunteer associations, colleges and universities connect students to a global movement to strengthen civil society..." (p.93). For example, Murphy and Rash (2008) argue that through service learning courses "students begin to realize that both social problems and correctives have a communal side that cannot be ignored" (p. 68). In this light, service learning has the ability to provide students with a greater understanding of what it means to be a fully engaged democratic citizen (Battistoni, 1997; Cone, 2003; Schamber \& Mahoney, 2008).

Of course, the benefits of service and community-based learning listed above are dependent on successful integration of these pedagogies into the classroom. Indeed, many in the service-learning community have raised concerns that this pedagogical tool has the potential to reinforce privilege and inequality. It is possible for students to interpret their service-learning experiences as providing or giving assistance to those in need. This interpretation may then preserve, or even spread, the belief that a group is vulnerable or powerless, especially when the service experience overlooks the resources of the local community or population (Camacho, 2004; Eby, 1998; Mitchell, 2008; Peterson, 2009). Eby (1998), for instance, argues that faculty often treat community partners as "subjects for experience and practice" (3). In doing so, the learning experience of the students is prioritized above the needs of the community members with which classes work (Eby, 1998; Steiner et al., 2011). Further, this model of service learning, in contrast to the positive potential outlined above, separates the college or university from the surrounding community rather than situating the institution as a part of the social system. Both of these problems reinforce the power dynamics between community partners and those in the academy, creating separation and hierarchy where unity and common goals should dominate.

In order to counter concerns about reciprocity and authority in service learning, students need to experience a learning process that directly addresses how to employ their class-based skills in new ways (Cone, 2003; Simmons, 2010). They must move the conversation around community-based learning from a discussion of the "doing" of service to an exploration of the learning that takes place during this type of experience. Therefore, it is essential that constructive and reciprocal service learning experiences integrate conversations and activities surrounding skill development into the course. An asset-based approach may be one way to achieve this goal. Here, we suggest that using elements of asset-based community development in a series of foundational activities is an effective means of readying students for service learning. Indeed, providing students with clear methods for participating in community work is one of the principles of good practice cited by the National Society for Experiential Education or NSEE (2014). Below, we define and describe asset-based community development, discuss how we have incorporated pieces of this approach into the classroom, and provide data to support the claim that it is a useful stepping-stone for greater community investment among students.

\section{Asset-Based Community Development}

Kretzman and McKnight (1993) developed asset-based community development in their seminal work Building Communities from the Inside Out: A Path Toward Finding and 
Mobilizing a Community's Assets. They express deep concerns over attempts to create social change that are initiated by outside actors and criticize traditional forms of community development as being needs-based and deficiencies focused. They argue that while the intentions are good, these models inadvertently perpetuate structures of hierarchy and power. As Peterson (2009) and Eby (1998) state in their discussions of community-based learning, the repeated giving of services perpetuates the perception that a group is vulnerable and powerless.

In contrast, the foundational principle of asset-based community development is that all communities are asset rich, thereby challenging the assumption that some communities are inherently reliant on outside assistance. In the asset mapping model, all communities have the ability to create sustainable growth from within. This growth is necessarily asset based, internally-focused, and relationship driven. Community development is constructed on solutions originating from the people and organizations within community itself. In focusing on solutions driven by community members, the top-down approach orchestrated by outside organizations is reconfigured. Beaulieu (2002) identifies the participants in asset-mapping as co-creators and colearners rather than understanding them as subjects in need of outside assistance. This approach offers another model for community development that asset mapping proponents argue is less hierarchical. In order to achieve this type of sustainable change, those engaging in assetmapping typically complete a series of steps including: identification of assets and canvassing, building a community profile and visual map of the community, create and implement an action plan.

Essential to Kretzman and Mcknight's process is the outlining and defining of community assets. Assets are understood as resources within the community that emerge from and are able to benefit the neighborhood. In the asset mapping process, these assets are identified through neighborhood canvassing and interactions with community members. The Bonner Curriculum offers an effective means of thinking more broadly about assets because it identifies several types, including "individual, institutional, organizational, governmental, cultural, and physical and land assets" (Bonner, 2012). For example, an assisted living community is, in and of itself, an institutional asset, but it also contains within it a diverse set of individual assets. The staff and residents themselves have their own skills, talents, experiences, leadership abilities, networks, and personality traits that are valuable and important pieces of both the assisted living residence and the larger community.

Assets are identified through community canvassing and then used to create a community profile. When building a community profile, it is essential to not only acknowledge the assets that exist, but also to understand the relationships between various assets. These relationships may stem from common skill sets, personal and professional relationships, similar goals, and economic and social connections. Next, community members create a visual asset map that graphically represents strengths within the community and identifies resources that can address community concerns (Bonner Curriculum, 2012; Cone, 1996). In doing so, the strengths and capacities within a community are brought to the fore. The process of asset mapping itself, therefore, has the potential to reinforce already existing connections. Once identified, these assets are mobilized in a plan created by community members to affect positive growth in the community.

Several organizations have developed specific processes for implementing asset mapping, including Kretzman and Mcknight's own Asset Based Community Development Institute at Northwestern University; Bonner Foundation (n.d.); Northwest Regional Educational Laboratory (1998); Cone, Kiesa, and Longo (1996); and Community Building Resources (1997). 
Additionally, asset mapping has been used to promote sustainable community growth by the U.S. Department of Housing and Urban Development, the UCLA Center for Health Policy Research, and Michigan State University. However, no scholarship exists on the potential use of asset mapping as a tool for service learning capable of promoting community awareness and engagement among students. Below we will explore ways to utilize some aspects of the assetmapping, which we will refer to as an asset-based approach, in higher education as a means of promoting understanding of and investment in local communities.

\section{Using an Asset-Based Approach in the Classroom}

The skills and principles of asset mapping can be adapted to teach concepts of community, promote student engagement with community, and prepare students for course experiences that rely on service-learning while helping them question entrenched power dynamics. While it may be difficult to complete the entire asset mapping process in a single course, our experience has shown that utilizing pieces of the asset mapping process successfully addresses several of the concerns about service learning discussed previously. In doing so, it prepares students for future service-learning.

We used an asset-based approach in three of our courses. The first course, Spanish Speaking World 285: Asset Mapping, Iowa Latinos, is a multi-disciplinary general education requirement primarily for juniors and seniors. The other two courses Sociology 101: Sociology in Action and Sociology 115: Introduction to Sociology, serve as introductions to the field of sociology and are taken primarily by first-year students. Both the Iowa Latinos course and Sociology in Action were taught during an intensive three-week January term. Introduction to Sociology was taught during the regular sixteen-week semester. Both the J-Term classes mapped the city in which our college is located, additionally the semester long sociology course and Iowa Latinos each mapped the campus community. According to the needs of each project, the campus community was either considered as an independent entity or embedded within the larger community.

Despite their differences in discipline and format, two central themes emerged in these courses: (1) an emphasis on understanding the relationship between individuals and the broader community and (2) the illumination of power structures. In the three classes, elements of an asset-based approach are utilized as a tool for engaging students with these concepts. This approach is suited to these common objectives given that it requires students to closely examine the structure and culture of a community in which they participate. This type of work in the classroom creates a solid foundation for students to engage with the community surrounding their institution. It also further guides the implementation of portions of asset mapping as a means of teaching concepts related to community and development and better prepare them for future community-based learning experiences.

We begin by introducing students to the philosophy of asset mapping. Course readings that teach the foundational principles of asset mapping are one way to achieve this goal, as are lectures and class discussions. When possible, we also facilitate conversations across courses in different disciplines that are each using an asset-based approach. Speakers experienced in this approach are another useful way to familiarize students with this perspective. For example, a speaker from the local Girl Scout council visited the two January-Term courses and discussed the importance of creating sustainable community change in the Girl Scout's Gold Award project. 
Once students have a firm handle on these ideas, they begin to use asset-based practices in their coursework. Identifying assets is the first step. As mentioned above, asset identification is completed through canvassing. For example, students in our courses toured neighborhoods, spoke with residents and community leaders, dialogued with class speakers, and examined materials from local businesses and organizations. Community members served as experts, and it was made clear that students were to learn from them, in particular when they were members of typically disenfranchised groups (e.g. homeless and impoverished people). At all points, we worked to ensure that as many positions and perspectives were made available to students as possible. Not only did this give a wider lens of the community, but it facilitates conversations about privilege, perspective, and conflict within and among communities.

Canvasing also requires students to notice resources they had previously overlooked (Kretzmann \& McKnight, 1993; Bonner Curriculum, 2012). For example, students in the Iowa Latino course noted the way in which open fields close to town might make beneficial play areas for neighborhood children. Similarly, students enrolled in Sociology in Action became aware of the skills, talents and depth of experiences available in the local homeless population. These conclusions allowed students to develop a greater appreciation for the asset rich nature of all communities, and recognize that every member of a community, as well as the features and history of the community, contribute to the creation of that society, and are, in actuality, creating community with the students on a daily basis. In doing so, students reconsidered preconceived notions about who and what are valuable pieces of the community. This is essential in assetbased activities because it deconstructs the idea that a community is dependent upon outside forces for its success and growth, thereby augmenting student awareness of the communities to which they belong. In this way, students are better prepared for future service learning experiences because they no longer read the given community as an area or group of people in need; instead, they view themselves as members of the local community, better understand the assets of a given space, and as a result, are more able to deconstruct issues of inequality, dominate/subordinate groups, and the lack of reciprocity often associated with service learning. After students complete the canvassing process, we ask them to develop a community profile and, subsequently, a community map. Figure 1 is an example of a visual community map developed during the Introduction to Sociology course by students concerned with parking on campus. It should be noted that this map includes not only assets from the college (e.g. Student Union, Residence Life, various parking lots), but also assets from the neighborhood surrounding the institution (neighbors and nearby residents, city police, etc). As is the case in canvasing, creation of a visual map aids students' understanding of the relationship between the college and the wider social system of which both the students and the institution are members. This can be seen, for example, in Figure 1 in which both campus neighbors and the police are connected to street parking, which is then related to overall student concerns of parking. However, because these relationships are not direct, this very basic map highlights potential spaces for new relationships that can be developed to promote sustainable community growth. This campusbased exercise reinforces the lessons of the foundational material and canvasing, while laying the groundwork for future work in the wider community by prompting students to understand both connections and gaps between community members and organizations. 


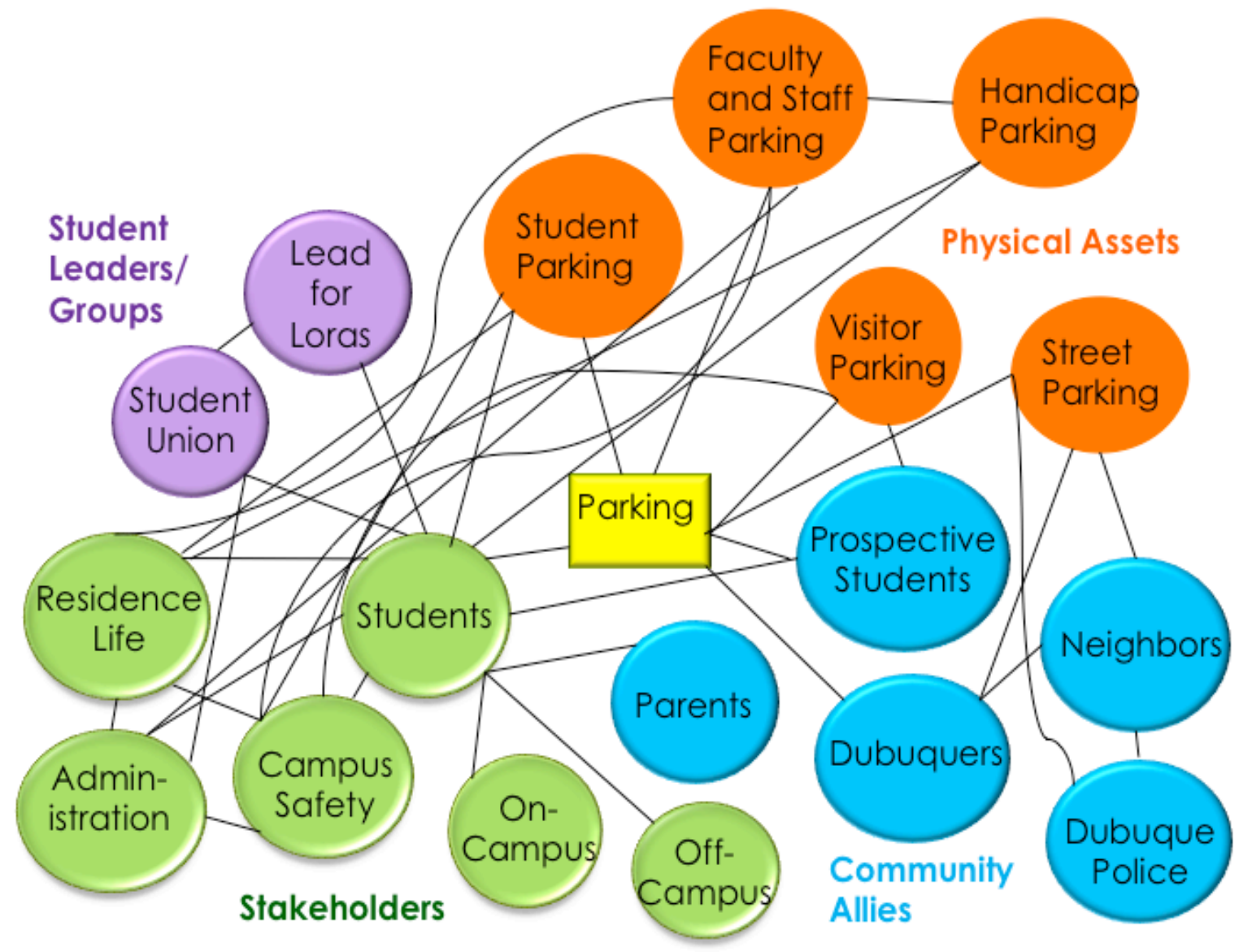

Figure 1: Visual Asset Map of Campus Parking

In our courses, students complete their asset-based projects by creating a plan of action. They develop a step-by-step plan to utilize the already existing assets and relationships highlighted by the community map to foster change. An example from Introduction to Sociology relates to student claims that more gym space was needed on campus. Students noted that funds had been set aside to purchase new gym equipment, but no plans had been made for the older equipment. There was also an old gym space that was seldom used. After creating the asset map, the student group realized that the old equipment and small gym space were both assets. Moving the old equipment to this smaller space solved two community concerns: the lack of space and what to do with the older, but still usable, gym equipment. Again, this type of activity better prepares students to have successful service learning experiences because, as discussed above, students often do not understand how to apply the skills learned in service learning experiences to larger contexts. In contrast, by creating an action plan, students realize how to transform what they have learned and done through an asset-based process into a concrete and tangible goal for the future. 


\section{Data and Methods}

To assess the success of these asset-based experiences, we collected data on the three courses in which we used activities based on asset mapping. As discussed above, two of these courses were introductory sociology courses geared toward first year and sophomore students while the other was an upper-level general education requirement for juniors and seniors. In total, 64 students both completed the asset mapping projects and consented to participate in the study. Additionally, a control was drawn from three classes. Like the test sample, participants in the control group were drawn from two introductory sociology and one upper-level general education course. In total, 155 students were included in the study. Two of asset-mapping based courses took place during a three week January-Term period, while all of the control groups were in regular semester-long classes.

Students were asked questions about their community involvement, prior communitybased learning, and their general understanding of both communities and the relationship between individuals and social systems (see the Appendix for the entire questionnaire). First, they were asked to identify the community activities in which they are involved. Students were free to define this for themselves, and answers ranged from direct service (e.g. serving in soup kitchens, Habitat for Humanity, volunteering in community organizations) to group membership (such as Girl Scouts, fraternal organizations, and religious activities) to on-campus experiences (athletic teams, school organizations, and the like). We then asked students about the specific types of community-based and experiential learning they have had in previous courses, including direct service, off-campus tours, speakers, internships, research, and asset mapping. Students reported extensive experience in experiential and community-based learning. As shown in Table 1 the most common experiences were direct service and speakers. In addition to types of experiences, we asked students how many of their previous courses included any of these components. Finally, students in both the control and test groups were asked how involved they feel in the community. Students were able to identify themselves as being Involved/Very Involved, Somewhat Involved, or Not Very Involved/Not at all Involved.

Table 1

\begin{tabular}{lc} 
Percent of Students Participating in Types of Experienti \\
\hline $\begin{array}{l}\text { Type of Experiential } \\
\text { Learning }\end{array}$ & Percent \\
\hline Speakers & $70 \%$ \\
Off-Campus Visits/Tours & $47.2 \%$ \\
Direct Service & $73.6 \%$ \\
Internships & $27.1 \%$ \\
Research & $45.8 \%$ \\
\hline
\end{tabular}

Students in the control group took the survey at the end of the semester. Those in the test group answered these questions before any discussion of asset-mapping occurred. They also took a post-test upon completion of their asset-based work. The post-test included the same questions as the pre-test as well as four additional questions. The new questions focused on student learning related to the asset-mapping activities. In particular, they were asked (1) if their experiences with asset-based work helped them develop a stronger grasp of the concept of 
community generally, (2) if they better understand the relationship between individuals and community, (3) if they better understand the mapped community and (4) if they feel more involved in the community as a result. While these questions assess student perceptions of their own learning, rather than changes in community involvement itself, they do indicate a change in the larger understanding of community and movement toward authentic and reciprocal community engagement that challenges the traditional power structures of community-based learning.

In the study, student responses were then analyzed to better understand the effects of using asset-mapping techniques in the classroom. A paired-sample t-test was used to examine changes in understanding and community involvement among the control group as a result of the asset-mapping experiences. Comparisons were also made between the test group, who participated in the asset-mapping based activities, and the control group, who did not, using an independent sample t-test. As discussed below, results overwhelmingly indicate support for taking an asset-mapping style approach in the classroom.

\section{Results}

The analyses show that students who engaged in asset-based work believe they gained a great deal from the experience. Indeed, of the 64 students in the test group, $100 \%$ either "Strongly Agreed" or "Agreed" that asset-based activities taught them about community (see Table 2). The results were similar when we asked students if they better understood the reciprocal relationship between individuals and communities after completing their asset-based projects. This time, 50\% of students "Strongly Agreed" and just over $48 \%$ of students "Agreed." We then asked students if, as a result of their asset-based experiences, they better understood the specific communities they mapped than before they began the mapping process. Sixty-three of the sixty-four students, or $98.4 \%$, responded that they did have a more complete picture of the localities and groups that were mapped.

These data suggest that students' theoretical knowledge improved as a result of assetbased techniques. It is also important to note that students' attitudes toward community changed as well. As shown in the last column of Table 2, when asked if an asset-based approach promoted their involvement in the community, nearly $48.5 \%$ of students either "Strongly Agreed" or "Agreed" while another 40.6\% "Somewhat Agreed." In total, then, $89.1 \%$ of students believe that their asset-based experience helped them become more engaged in the community. This change in belief is important because it indicates that students now understand themselves as being part of the community and highlight how the co-creator philosophy of asset mapping can alter student perception of community dynamics.

This belief is made manifest in comparison of pre and post-test data. As shown in Table 3 , students report being more involved in the community after participating in asset-based projects than before. A paired-sample t-test was used to determine if the difference between the pre- and post-tests were significant. The results indicate that a significant difference does exist between the two groups. Although the actual change is minimal, there was movement from the "somewhat involved" to "involved" category; it is also important to keep in mind that two-thirds of the students were in courses that lasted only three weeks. In a short time, then, asset-based work significantly increased the extent to which students feel involved in their community. 
Garoutte, L., \& McCarthy-Gilmore, K.

Table 2

Frequencies of Student Responses to Asset Mapping, $N=64$

\begin{tabular}{lllll}
\hline & $\begin{array}{l}\text { Taught } \\
\text { Concept } \\
\text { of Community }\end{array}$ & $\begin{array}{l}\text { Taught } \\
\text { Relationships } \\
\text { Between } \\
\text { Individuals and } \\
\text { Community }\end{array}$ & $\begin{array}{l}\text { Better } \\
\text { Understand } \\
\text { The Mapped } \\
\text { Community }\end{array}$ & $\begin{array}{l}\text { Promoted My } \\
\text { Involvement in } \\
\text { the Community }\end{array}$ \\
\hline Strongly Agree & 32 & 32 & 36 & 3 \\
Agree & $50.0 \%$ & $50.0 \%$ & $56.3 \%$ & $4.7 \%$ \\
& 32 & 31 & 27 & 28 \\
Somewhat & 0 & $48.4 \%$ & $42.2 \%$ & $43.8 \%$ \\
Agree & $0 \%$ & 0 & 0 & 26 \\
Somewhat & 0 & $0 \%$ & $0 \%$ & $40.6 \%$ \\
Disagree & $0 \%$ & 0 & 0 & 0 \\
Disagree & 0 & $0 \%$ & $0 \%$ & $0 \%$ \\
& $0 \%$ & 1 & 1 & 7 \\
Strongly & 0 & $1.6 \%$ & $1.6 \%$ & $10.9 \%$ \\
Disagree & $0 \%$ & 0 & 0 & 0 \\
\hline
\end{tabular}

Table 3

Paired-Sample T-Test of Community Involvement

\begin{tabular}{llll}
\hline & Pre-Test & Post Test & Significance \\
\hline $\begin{array}{l}\text { "Overall, how involved are } \\
\text { you in your community" }\end{array}$ & & 2.18 & $.012^{*}$ \\
\hline
\end{tabular}

$\mathrm{p}<.05$; Responses are scaled as follows: 1=Very Involved, 2=Involved, 3=Somewhat Involved, 4=Not Very Involved, 5=Not At All Involved

The extent to which these students feel involved in their community was also compared to the control group. An independent sample t-test was used to compare the answers of the control group and the test group to the question, "Overall, how involved are you in the community?" As shown in Table 3, there is a significant difference between the control group and the asset-based group. Students enrolled in the asset-based course were significantly more likely to feel involved in their communities at the end of their experience than those who did not 
engage in asset-based projects. Again, the small but significant change is especially impressive considering the short duration of two of the three classes.

Table 4

Independent Sample T-Test of Community Involvement

\begin{tabular}{lc}
$\frac{\text { Independent Sample T-Test of Community Involvement }}{\text { Mean }}$ \\
\hline Control Group & 2.25
\end{tabular}

Asset Mapping Group $\quad 1.94$

$\mathrm{P}=.-2$; Responses are scaled as follows: 1=Very Involved/Involved, 2=Somewhat Involved, $3=$ Not Involved

It should be noted that there was a significant difference in community involvement between the test group and the control group. Chi-square tests found that students who participated in the asset-based classes were more likely to have taken previous classes with community-based or experiential learning. In order to control for this we conducted additional analyses with only students who had previously participated in classes with a community component. The results, shown in Table 5, continue to show that the asset-mapping students identify themselves as being more involved in the community. The means are similar to those shown in the previous table, though the significance is stronger $(\mathrm{p}<.01)$. In other words, even among students with prior service and community-based learning experiences students who participated in asset-based work feel more connected to their community than those who did not do any asset-mapping activities.

Table 5

Independent Sample T-Test of Community Involvement Among Students with Previous CBL experience

\begin{tabular}{ll}
\hline & Mean \\
\hline Control Group & 2.35
\end{tabular}

Asset Mapping Group $\quad 1.88$

$\mathrm{p}=.01$; Responses are scaled as follows: 1=Very Involved/Involved, 2=Somewhat Involved, $3=$ Not Involved

In sum, we find that students believe they better understand the concept of community, the relationship between individuals and communities; the specific communities that were mapped, and they are more involved in these communities. We argue that these data are a result of the focus of this asset-based approach on reciprocity amongst all community members. The reciprocal view of community emphasizes the power of ordinary individuals and the ways in which interdependencies can create change. Further, projects founded on asset-based techniques inspire students to see themselves as members of the mapped communities, which is a step toward minimizing the "us" versus "them" attitudes of colleges and their surrounding 
communities. In these ways, using this asset-based approach as a precursor to service learning can address power hierarchies, even when the focus of the asset-based project is on-campus. This is beneficial for later service learning experiences, which, as we have seen above, are often criticized for reinforcing hierarchal relationships.

\section{Conclusions}

Using elements of asset-based community development practices may be one way to produce students who are more tightly engaged in the larger communities surrounding their institutions. Results indicate that students who participate in asset-based work better understand the concept of community and the ways in which individuals are connected to their community, thus making asset-based activities useful for classes that explore those ideas. As mentioned above, this could include courses in the areas of social work, criminal justice, language study, and education as well as other areas of study. For example, students in advanced Education courses could utilize pieces of asset-mapping before student teaching to explore the connections between a school where they might teach in the future and the local community. This would guide students in understanding the school and the community members as assets with developed and undeveloped connections between them. Students could then create solutions and suggest means of utilizing resources to address concerns. This would prepare the students for work with both children and adults in a future professional position. Colleges and universities could also incorporate asset-based work into first-year or sophomore seminars, or into programs that focus on community service. Many colleges and universities, for example, now have courses that introduce first year students to college life. Including asset-based projects into such courses would help embed students not only in their school community and wider neighborhood, but could also demonstrate the importance of active learning and community involvement from the beginning of their college careers.

As we discuss above, classes do not need to incorporate all aspects of the asset-mapping approach when implementing this technique. That said, an asset-mapping course, or semester long project embedded in a course, would allow students to more fully engage with each step of the asset mapping approach. Students could spend more time canvassing, engaging directly with community members, developing the map and creating solutions. Dedicating more time to each of these aspects of asset mapping would take students into the community to work directly with community partners. Our work with asset mapping indicates that this type of experience, possibly including developing solutions for community based issues, could potentially increase levels of community involvement and, therefore, foster even greater growth than the short asset mapping experiences we implemented.

While the results indicate impressive student learning and growth as a result of assetbased experiences, more research is needed to understand the larger context for this type of work. A larger sample size with representation from several types of colleges and universities would be beneficial. Size of the surrounding community and the institution's relationship with its neighbors should also be considered. Likewise, community response to and experience with asset-based work should be examined. Still, the results are promising. It provides a useful starting point for addressing the power issues some scholars argue are inherent to service and community-based learning while also creating a basis for more genuine partnerships with community partners. This is key when preparing students for future work in the community as it directly challenges many of the issues surrounding community-based learning and provides 
students with tools to engage reciprocally with their community without participating in hierarchical or one-way community partnerships. As such, this asset-based approach can play a role in creating real and authentic campus-community partnerships that strive to engage students as members of the community from the outset and throughout their service learning courses.

\section{Acknowledgements}

The authors would like to thank Maggie Baker, Service Learning Coordinator at Loras College, for her guidance in using asset-based methods as well as for her support of our research. We would also like to thank the anonymous reviewers for the helpful suggestions which improved this paper.

\section{Appendices}

\section{Appendix 1: Pre-Test/Control Survey}

1. What types of community activities are you involved in? (At home and on campus)

2. What types of community activities have been part of your classes? Check all that apply:

Volunteering / Service work

Field trips / Off-campus tours

Speakers

Internships / Work study

Research

Asset Mapping

None

Other. Please list:

3. How many of your classes include activities in the community?

None

$1-2$

$3-5$

6 or more

4. Overall, how involved do you feel in the larger community?

Very involved

Involved

Somewhat involved

Not very involved

Not at all involved 
Appendix 2: Post-test

1. What types of community activities are you involved in? (At home and at on campus)

2. What types of community activities have been part of your classes? Check all that apply: Volunteering / Service work

Field trips / Off-campus tours

Speakers

Internships / Work study

Research

Asset Mapping

None

Other. Please list:

3. How many of your classes include activities in the community? Select one answer.
None
$1-2$
3-5
6 or more

4. Overall, how involved do you feel in the larger community? Select one answer.

Very involved

Involved

Somewhat involved

Not very involved

Not at all involved

5. Did asset mapping promote your involvement in the community? Select one answer.

Strongly agree

Agree

Somewhat agree

Disagree

Strongly disagree

\section{References}

Thinking About Community Capacity Building and Asset Mapping. (1997). Community building resources. MACJS Publishing: Spruce Grove, Alberta, Canada.

Basinger, N., \& Bartholomew, K. (2006). Service learning in nonprofit organizations: Motivations, expectations, and outcomes. Michigan Journal of Community Service Learning, Spring, 15-26. 
Battistoni, R. M., Longo, N. V., \& Jayandadhan, S. R. (2009). Acting locally in a flat world: Global citizenship and the democratic practice of service-learning. Journal of Higher Education Outreach and Engagement, 13 (2), 89-107.

Bonner Foundation. (2012). Community asset mapping: A critical strategy for service. Retrieved from: http://www.bonner.org/resources/modules/modules_pdf/BonCurCommAssetMap.pdf>

Colby, S., Bercaw, L., Clark, A. M., \& Galiardi, S. (2009). From community service to servicelearning leadership: A program perspective. New Horizons in Education, 57 (3), 20-31.

Cone, R. E., Kiesa, A., \& Longo, N. V. (2006). Raise your voice (A student guide to making positive social change). Boston, MA: Campus Compact.

Dorfman, D. (1998). Mapping community assets workbook. Strengthening community education: The basis for sustainable renewal. Portland, OR: Northwest Regional Educational Laboratory.

Eyler, J., \& Giles, D. E. (1999). Where's the learning in service-learning? San Francisco, CA: Jossey-Bass.

Goddard, J., \& Chatterton, P. (2000). The response of higher education institutions to regional needs. European Journal of Education, 35 (4), 475-496. doi: 10.1111/1467-3435.00041

Kretzmannn, J. P., \& McKnight, J. L. (1993). Building communities from the inside out: A path toward finding and mobilizing a community's assets. Skokie, Il: ACTA Publications.

Lowery, D., May, D. L., Duchane, K. A., Coulter-Kern, R., De’Bryant, M. P. V., Pomery, J. G., \& Bellner, M. (2006). A logic model of service-learning: Tensions and issues for further consideration. Michigan Journal of Community Service Learning, Spring, 47-60.

Mitchell, T. D. (2008). Traditional vs. critical service-learning: Engaging the literature to differentiate two models. Michigan Journal of Community Service Learning, Spring, 50-65.

Murphy, J. W., \& Rash, D. (2008). Service-learning, contact theory, and building black communities. The Negro Educational Review, 59 (1-2), 63-78.

National Society for Experiential Education. (2013). Eight principles of good practice for all experiential learning activities. Retrieved from: http://www.nsee.org/index.php?view=article\&catid=20: ite-content\&id=79:8principles\&format $=$ pdf

Peterson, T. H. (2009). Engaged scholarship: Reflections and research on the pedagogy of social change. Teaching in Higher Education, 14 (5), 541-552. doi: 10.1080/13562510903186741

Schamber, J. F., \& Mahoney, S. L. (2008). The development of political awareness and social justice citizenship through community-based learning in a first-year general education seminar. The Journal of General Education, 57 (2), 75-99. doi: 10.1353/jge.0.0016 